\title{
Leaching foams for copper and silver dissolution : a proof of concept of a more environmentally-friendly process for the recovery of critical metals
}

Pierre Trinh' ${ }^{1}$, Alesya Mikhailovskaya ${ }^{1}$, Mengxue Zhang ${ }^{2}$, Patrick Perrin ${ }^{1}$, Nadège

Pantoustier $^{1}$, Grégory Lefèvre ${ }^{* 2}$, Cécile Monteux ${ }^{*, 1}$

1 Laboratoire Sciences et Ingénierie de la Matière Molle, UMR 7615, ESPCI Paris, CNRS, PSL

Research University, Sorbonne Université, 10 rue Vauquelin, 75231 Paris cedex 05, France

2 Institut de Recherche de Chimie Paris, Chimie Paristech, CNRS, PSL Research University, 75005 Paris cedex 05, France

cecile.monteux@espci.fr

gregory.lefevre@chimieparistech.psl.eu

KEYWORDS. Foams, leaching, metals, recycling, hydrometallurgy 
ABSTRACT The recovery of metals from WEEE, Waste from Electrical and Electronic Equipment, is a major challenge to preserve natural resources. Hydrometallurgy, which consists in leaching metals is a promising method but generates large amounts of polluting effluents. In this study we design aqueous leaching foams, composed of $90 \% \mathrm{v} / \mathrm{v}$ of gas and $10 \% \mathrm{v} / \mathrm{v}$ of $\mathrm{HCl}$ solution to oxidize and dissolve copper. We take advantage of the oxidizing power of the dioxygen $\left(\mathrm{O}_{2}\right)$ present in the air bubbles whose fast transfer through the foams enables an efficient oxidation of copper. We then extend the concept of leaching foams to another gas, ozone, to oxidize silver (Ag). We finally show that using an anionic surfactant to complex cupric ions helps improving the dissolution of the metal. These promising results open new recycling routes for metals contained in WEEE, with a lower environmental footprint.

\section{Introduction}

The recovery of the wide variety of metals in WEEE (Waste from Electrical and Electronic Equipment) also called e-waste is becoming a major challenge to preserve natural resources while treating a large amount of waste (1-3). Hydrometallurgy, based on leaching solutions containing oxidants or acids to extract metals, which was traditionally used for the mining industry for ore extraction is also a promising route for the recovery of metals from WEEE (such as Platinum Group metals, $\mathrm{Au}, \mathrm{Ag}, \mathrm{Cu})(4-9)$. Hydrometallurgy is particularly suitable for local and short scale installations and is therefore an interesting alternative to pyrometallurgy which consists in an energy-intensive process where the wastes are smelted at high temperature (10). Moreover by carefully choosing the leachants used, it is possible to obtain a selective process maximizing the extraction of precious metals while minimizing the extraction of non precious metals (11). The 
development of hydrometallurgy is hampered by the fact that this process generates large amounts of polluting effluents such as cyanide or sulfuric acid (12). To address this issue, eco-friendly processes are emerging such as the ones that use eco-friendly leachants (formic acid or potassium persulfate (13) or bioleaching methods, based on microbes eventually combined with chelatants (13). In the present study, we choose another route which consists in reducing the amounts of leaching effluents by developing leaching aqueous foams. Foams are collections of bubbles stabilized by surfactants and contain less than $25 \%$ in volume of liquid and therefore appear as a promising way of decreasing the environmental footprint of hydrometallurgy.

Aqueous foams are used in environmentally relevant applications for waste water treatment (14) or nuclear waste retreatment (15-16). These applications rely on flotation, a process which promotes the concentration of impurities at the surface of bubbles and in the liquid films and channels connecting the bubbles, which can then be collected easily as they float at the top of the water sample. The nature of the species that can be concentrated in foams is multiple: ions (1718), ores (19), minerals $(20-21)$, or proteins $(22,23)$. A major advantage of foams is that they contain, by definition, between 74 and $99 \%$ of air and consequently very little volume of liquid hence they are good candidates for a reduction of effluents volumes during these processes (24). Moreover, foams are remarkably versatile and the surfactant used to achieve their stabilization can be chosen to obtain specific properties, such as in particle or ion flotation processes where ionic surfactants can complex the particles or ions to be recovered which allows a more efficient concentration process (17-23).

In the above applications, the bubble gas, usually air, is not chemically active and is only used to produce bubbles that promote particle flotation. Reactive gases such as $\mathrm{O}_{2}$ or $\mathrm{O}_{3}$ may confer some 
oxidizing reactivity to aqueous foams that can be useful for applications where leaching is required such as in hydrometallurgy.

In the present study we design leaching foams to oxidize and dissolve metals. We first establish a proof of concept for a standard metal, copper $(\mathrm{Cu})$, using a foam stabilized by a non-ionic surfactant, polyoxyethylene alkyl ether, and containing hydrochloric acid $(\mathrm{HCl})$. We take advantage of the oxidizing power of the dioxygen $\left(\mathrm{O}_{2}\right)$ present in the air bubbles and demonstrate that the fast transfer of $\mathrm{O}_{2}$ through the foams enables a rapid and efficient oxidation of copper. By using ozone $\left(\mathrm{O}_{3}\right)$, a gas with a high electrochemical potential, we show that these foams can be applied to the leaching of silver, a more precious metal. Finally we demonstrate that the complexation of cupric ions using an anionic surfactant, sodium dodecyl sulfate (SDS) helps improving the dissolution process of the metal. These promising results open new recycling routes for metals contained in e-waste, with a lower environmental footprint as they would result in a low liquid waste volume and a smaller amount of oxidizing chemicals.

\section{Materials and Methods}

The acid solutions are prepared by dilution of concentrated hydrochloric acid (37\%, SigmaAldrich) or sulfuric acid (Sigma Aldrich) at a concentration of 0,1 or $1 \mathrm{M}$ with MilliQ water (18,2 $\left.\mathrm{M} \Omega . c m @ 25^{\circ} \mathrm{C}\right)$. The nonionic surfactants Brij ${ }^{\circledR} \mathrm{O} 10\left(\mathrm{C}_{18} \mathrm{H}_{35}\left(\mathrm{OCH}_{2} \mathrm{CH}_{2}\right)_{\mathrm{n}} \mathrm{OH}, \mathrm{n} \sim 10 \mathrm{CAS} 9004-\right.$ 98-2) and Brij ${ }^{\circledR} 23\left(\mathrm{CH}_{3}\left(\mathrm{CH}_{2}\right)_{10} \mathrm{CH}_{2}\left(\mathrm{OCH}_{2} \mathrm{CH}_{2}\right)_{\mathrm{n}} \mathrm{OH}, \mathrm{n} \sim 23 \mathrm{CAS} 9002-92-0\right)$ and the anionic surfactant SDS (Sodium dodecyl sulfate, purity $\geq 99,0 \%$ CAS 151-21-3) are purchased from Sigma-Aldrich. The gas used are either filtered air, pure nitrogen (supplied by Air Liquide), or a mix between dioxygen and ozone produced by an ozone generator (Anseros DE), ozone generator, COM-AD-01 with a maximum capacity of $4 \mathrm{gO}_{3} / \mathrm{h}$ plugged to a flow controller (Gilmont ${ }^{\circledR}$ ) that 
ensures gas flowrate around $40 \mathrm{ml} / \mathrm{min}$. When $\mathrm{N}_{2}$ is used to make the foam, $\mathrm{N}_{2}$ is bubbled in the solution during 30 minutes to remove dissolved dioxygen. During foaming, air and nitrogen are bubbled into perfluorohexane $\left(\mathrm{C}_{6} \mathrm{~F}_{14}-\mathrm{CAS} 355-42-0\right.$ as traces of this water-insoluble gas in the bubbles enable to slow down Oswald ripening and increase the foam stability (24-25). The experiment consists in stirring either a copper plate, $(2 \mathrm{~cm} \times 2 \mathrm{~cm} \times 675 \mu \mathrm{m}$, purchased at Alfa Aesar, purity $99.9 \%$ ) or a silver plate ( $2 \mathrm{~cm} \times 2 \mathrm{~cm}$ x $250 \mu \mathrm{m}$, purity $99.9 \%$, purchased at SigmaAldrich) at $40 \mathrm{rpm}$ for five hours (using a RZR 2020 stirrer from Heidolph), in a 3 neck round bottom flask filled with $100 \mathrm{~mL}$ of foam or solution. For foam experiments (Figure $1 \mathrm{~b}$ ), $15 \mathrm{~mL}$ of the surfactant solution containing $\mathrm{HCl}$ or $\mathrm{H}_{2} \mathrm{SO}_{4}$ are poured into the flask and the gas is then injected through a porous fritted glass (pore diameter: $16-40 \mu \mathrm{m}$, supplied by ROBU Glasfilter Geräte $\mathrm{GmbH}$ ) at a flow-rate of $60 \mathrm{~mL} /$ minute for about two minutes to reach a total foam volume of $100 \mathrm{~mL}$, therefore the liquid fraction of the foams is of the order of $15 \%$. The initial bubble diameter is approximately $200 \mu \mathrm{m}$ is measured by optical microscopy. Because of partial foam collapse, of the order of $10 \%$ of the foam volume after 25 minutes, the gas is injected for 20 seconds every 25 minutes to keep the foam volume constant. For solution experiments (Figure 1a), the copper plate is directly stirred into $100 \mathrm{~mL}$ of solution. During experiments where air is bubbled in the solution without a surfactant, bubbling is done continuously for five hours at a flow rate of $60 \mathrm{~mL} /$ minute. In a set of experiments, the gas atmosphere above the foam or the solution is changed by applying a gentle gas flow above the foam or solution and parallel to their surface. This flow is gentle enough to avoid bubbling or perturbation of the surface.

After five hours, the final mass of the copper or silver plate is subtracted from the initial mass to calculate the total dissolved copper amount $(\Delta \mathrm{m}(\mathrm{Cu}))$. Samples of $300 \mu$ lare also regularly taken in the drained liquid of the foam or directly in solution. They are further diluted with $14.7 \mathrm{ml}$ of 
$1 \mathrm{M}$ hydrochloric or sulfuric acid solution and then analyzed with an ICP-OES (Inductively Coupled Plasma -Optical Emission Spectrometry ThermoScientific ICAP 6300 Duo) spectrometer to measure the amount of copper or silver dissolved above time.

\section{Results and discussion}

\section{Oxidation of Copper by $\mathrm{O}_{2}$ in $\mathrm{HCl}$ foams}

To evaluate the effectiveness of aqueous foams to oxidize metals and take advantage of the gas contained in the bubbles, we first choose to study the oxidation of a copper plate $(\mathrm{Cu})$ into cupric ions $\left(\mathrm{Cu}^{2+}\right)$ by the dioxygen $\left(\mathrm{O}_{2}\right)$ contained in the foam air bubbles in the presence of protons according to the following reaction (1)

$2 \mathrm{Cu}+\mathrm{O}_{2}+4 \mathrm{H}^{+} \rightarrow 2 \mathrm{Cu}^{2+}+2 \mathrm{H}_{2} \mathrm{O}$

To decouple the action of the protons from that of the oxidizing gas, $\mathrm{O}_{2}$, we choose to acidify the solution with hydrochloric acid $(\mathrm{HCl})$, which is known to be inefficient for the dissolution of metals in the absence of an oxidant. Indeed, metals such as copper are usually dissolved either by using an oxidizing acid such as nitric acid $\left(\mathrm{HNO}_{3}\right)(26)$ or by combining a non-oxidizing acid such as $\mathrm{HCl}$ or $\mathrm{H}_{2} \mathrm{SO}_{4}$ with a dissolved oxidant such as $\mathrm{Fe}^{3+}(27)$.

We compare the dissolution process of a copper plate stirred in a 3 neck bottle flask containing either $100 \mathrm{~mL}$ of a $0.1 \mathrm{M} \mathrm{HCl}$ solution (Figure 1a) or $100 \mathrm{~mL}$ of an aqueous foam obtained by foaming $15 \mathrm{~mL}$ of $0.1 \mathrm{M} \mathrm{HCl}$ solution using a porous fritted glass (Figure 1b). Using Inductively Coupled Plasma, ICP, we measure the concentration of $\mathrm{Cu}^{2+}$ ions generated in the foams and in the solution during the experiment from which we deduce the mass of copper dissolved over time (squares in Figure 1c). 
Figure 1. Dissolution of a copper plate in a solution and in a foam. (a) Experimental set-up of a copper plate stirred in a 3 neck bottle flask containing $100 \mathrm{~mL}$ of a 0.1M HCl solution or (b 100 $m L$ of an aqueous foam obtained by foaming $15 \mathrm{~mL}$ of $0.1 \mathrm{M} \mathrm{HCl}$ solution. (c) Mass evolution of the $\mathrm{Cu}$ plate $(\mathrm{Am}(\mathrm{Cu}))$ either in $100 \mathrm{ml}$ of a $[\mathrm{HCl}]=0.1 \mathrm{M}$ solution or in $100 \mathrm{ml}$ of foam containing $15 \mathrm{~mL}$ of $[\mathrm{HCl}]=0.1 \mathrm{M}$ and $\left[\mathrm{Brij}{ }^{\circledR O} \mathrm{O} 10\right]=0.05 \mathrm{M}$. The squares are results obtained using $\mathrm{ICP}$ experiment while the filled circles are obtained by weighing the copper plate after five hours. In both experiments air is used as atmosphere above the solutions and foams as well as to produce de foam bubbles.

In addition to the ICP experiment, we measure the weight of the copper plate before and after five hours of experiments to deduce the mass of $\mathrm{Cu}$ dissolved after 5 hours (circles in Figure 1c). The results obtained by both methods are consistent and they show that the dissolution of the copper plate is much more efficient in the $\mathrm{HCl}$ foam than in the $\mathrm{HCl}$ solution. After five hours, the mass 
of $\mathrm{Cu}$ dissolved in the foam is eight times higher than in the solution, while the amount of $\mathrm{HCl}$ solution used is almost ten times lower. Knowing the surface of the plate we obtain a rough estimation of the thickness of $\mathrm{Cu}$ removed by the leaching foams and find that it is of the order of $125 \mu \mathrm{m}$, which is of the same order of magnitude as standard $\mathrm{Cu}$ thicknesses on PCBs (ranging between 17 and $170 \mu \mathrm{m})$.

We also perform an experiment in which the plate is stirred in a $100 \mathrm{~mL} \mathrm{HCl}$ solution without any surfactant while air is continuously bubbled through the solution for five hours, using the same porous stick. In that case the amount of $\mathrm{Cu}$ dissolved after five hours is only $5 \mathrm{mg}$, similarly to the case where air is not bubbled in the $100 \mathrm{~mL} \mathrm{HCl}$ solution. In that case, the air bubbles quickly rise to the top of the flask and probably do not have time to dissolve and transfer toward the copper plate. Comparing the results obtained with and without surfactant enables us to confirm that in the absence of surfactant, even with continuous bubbling, the dissolution process is much less efficient than using foams, for which air is only bubbled for a few minutes over five hours.

From the slopes of the curves presented in Figure 1c, one can see that the reaction rate is higher in the case of the foam than in solution. However the dissolution rate slows down during the process. To determine the reaction limiting reactant, we performed a mass balance (Table 1) to calculate the amount of reactants, $\mathrm{H}^{+}$and dissolved $\mathrm{O}_{2}$, initially present in the foam and in the solution. 


\section{Initial quantity Consumed quantity}

(mol) (mol)

\begin{tabular}{|c|c|c|c|}
\hline Solution & $\mathrm{H}^{+}$ & $10^{-2}$ & $1.510^{-4}$ \\
\hline & $\mathrm{O}_{2}$ & $2.610^{-5}$ & $3.910^{-5}$ \\
\hline Foams & $\mathrm{H}^{+}$ & $1.510^{-3}$ & $1.410^{-3}$ \\
\hline & $\mathrm{O}_{2}$ & $810^{-4}$ & $3.410^{-4}$ \\
\hline
\end{tabular}

Table 1. Mass balance of the reactants. The number of moles $O_{2}$ initially present in the systems is calculated by taking the solubility of the gas in water. In the case of the foam the amount of $\mathrm{O}_{2}$ corresponds to both the bubbles and the foam aqueous phase. The consumed amount of moles corresponds to the measured mass loss of $\mathrm{Cu}$ according to Figure $1 \mathrm{c}$.

The solubility limit of $\mathrm{O}_{2}$ under ambient temperature and pressure is $2.510^{-4} \mathrm{M}$ whereas the $\mathrm{H}^{+}$ concentration is $0.1 \mathrm{M}$. These two concentrations are multiplied by the volume of liquid, either $100 \mathrm{~mL}$ or $15 \mathrm{~mL}$ for the solution or the foam respectively. In the case of the foams, the amount of $\mathrm{O}_{2}$ present in the foam bubbles, i.e. $85 \mathrm{~mL}$ of air containing $21 \%$ of $\mathrm{O}_{2}$ is of the order of $810^{-4}$ $\mathrm{M}$, which is 100 times higher than the amount of $\mathrm{O}_{2}$ dissolved in the continuous phase, of the order of $2.610^{-6} \mathrm{M}$. We then calculate the amount of reactants corresponding to the experimentally measured mass of dissolved copper consumed during Reaction (1). By comparing these sets of 
values for the case where the reaction is occurring in a solution, we deduce that protons are in large excess meaning that $\mathrm{O}_{2}$ is the limiting reactant. Moreover, the amount of $\mathrm{O}_{2}$ used for the reaction is higher than the amount of $\mathrm{O}_{2}$ initially dissolved in the solution. Consequently, some $\mathrm{O}_{2}$ from the atmosphere above the solution dissolves into the solution during the reaction. Performing the same analysis for the foam, we find that $\mathrm{O}_{2}$ is in excess, owed to the large amount present in the bubbles and that the limiting reactant is $\mathrm{H}^{+}$explaining the slowing down of the chemical reaction after 150 minutes in the foam. This first set of experiments shows that foams enable to obtain a better dissolution of $\mathrm{Cu}$ than the solutions even when air is bubbled without a surfactant. In the case of solutions, $\mathrm{O}_{2}$ is the limiting reactant while in foams $\mathrm{H}^{+}$is the limiting reactant. We suggest that the dissolution and transfer of $\mathrm{O}_{2}$ toward the copper plate is faster for foams than for solutions.

To understand how the transfer of $\mathrm{O}_{2}$ proceeds inside the foams and how it influences the chemical reaction, we perform experiments where air is replaced by an inert gas, Nitrogen $\left(\mathrm{N}_{2}\right) . \mathrm{N}_{2}$ is used either to produce the foam bubbles or to control the atmosphere above the foams by introducing a gentle flux in the atmosphere above the foams during the reaction. This protocol allows us to find that the composition of the gas atmosphere above the foams plays a greater role than the gas present in the bubbles. Indeed, when the atmosphere is composed of air and hence, contains $\mathrm{O}_{2}$, the mass of oxidized and dissolved $\mathrm{Cu}$ is at least ten times higher than in the case of an atmosphere only composed of $\mathrm{N}_{2}$, irrespective of the gas used to produce the foam bubbles (Figure 2). As an example, with air bubbles, the amount of dissolved $\mathrm{Cu}$ after five hours is only a few mg with a $\mathrm{N}_{2}$ atmosphere while it is $40 \mathrm{mg}$ using an air atmosphere. Moreover in the two situations where $\mathrm{O}_{2}$ is present in the atmosphere the reaction kinetics is very similar (not shown), suggesting that a fast transfer of gas between the foam bubbles and the atmosphere proceeds and equilibrates the gas activities across the flask. In other words, the gas atmosphere acts as an infinite reservoir which 
controls the gas activity inside the bubbles. Furthermore it suggests that the $\mathrm{O}_{2}$ transfer through the $\mathrm{HCl}$ foams is much faster than in the $\mathrm{HCl}$ solutions because it diffuses through the aqueous liquid films between the foam bubbles, which are very thin, usually of the order of tens of nanometers.

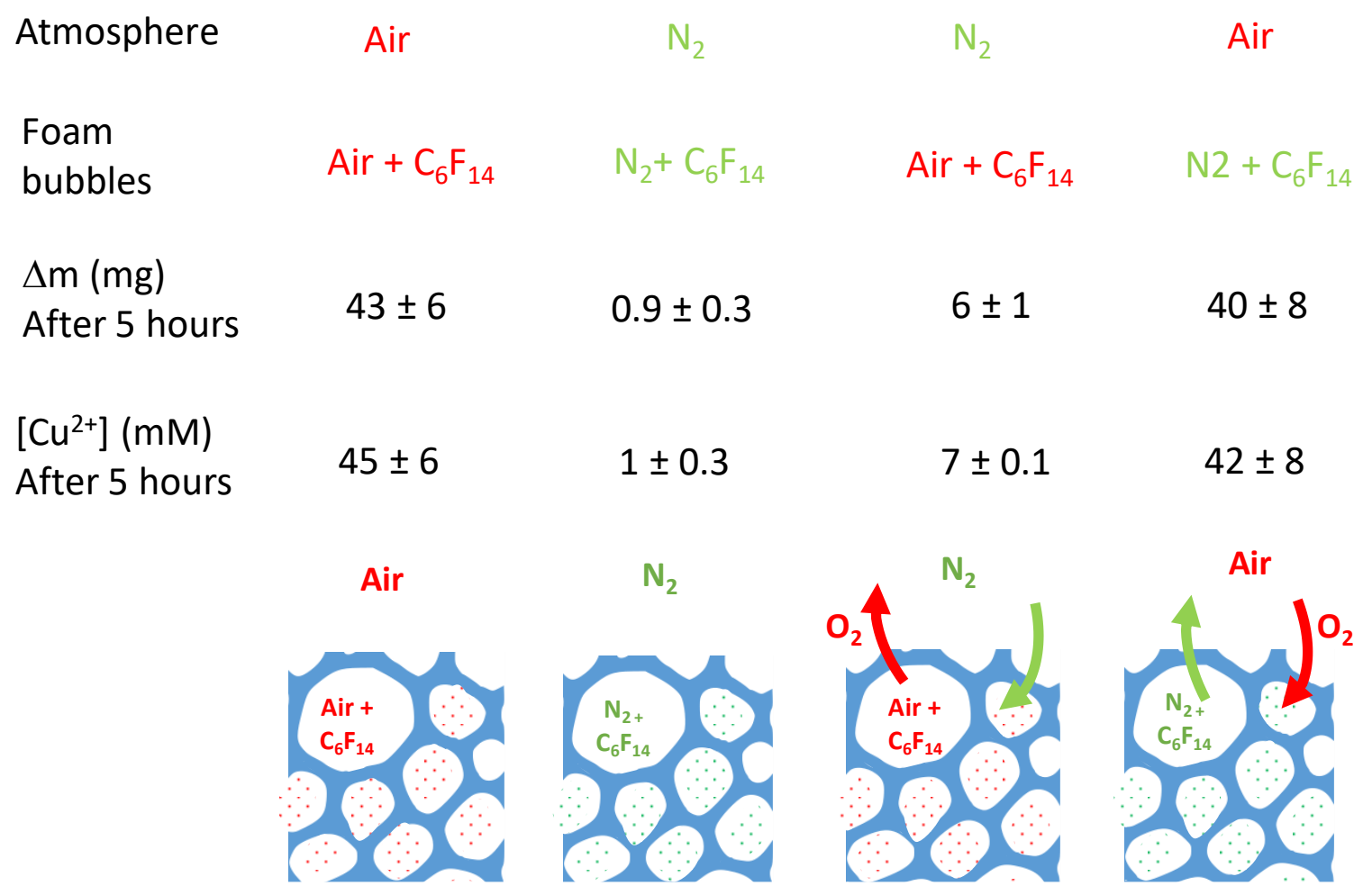

Figure 2. Influence of the foam bubbles and atmosphere gas composition on the copper mass

dissolved. The mass of copper dissolved $\Delta m_{C u}$, is obtained by weighing the copper plate after five hours or measuring the cupric ion concentration $\left[\mathrm{Cu}^{2+}\right]$ using $\mathrm{ICP} .[\mathrm{HCl}]=0.1 \mathrm{M}$

Extending the leaching foam concept to a noble metal (Ag) and to another reactive gas, ozone $\left(\mathbf{O}_{3}\right)$ 
This first set of experiments is a proof of concept showing that foams are efficient reaction media for the oxidation of copper by $\mathrm{O}_{2}$ as they enable the fast transfer of the gaseous reactant through the foam. We now investigate means to extend this concept to noble metals, such as silver (Ag), which is also present in WEEE wastes such as printed circuit boards. We replace the copper plate used in the protocol described above by a silver plate and we use $\mathrm{H}_{2} \mathrm{SO}_{4}$ instead of $\mathrm{HCl}$ to avoid silver chloride precipitation. Indeed silver sulfate is several orders of magnitude more soluble than silver chloride and a simple calculation (not shown) shows that the silver concentration can be higher than $10 \mathrm{mM}$ in presence of $1 \mathrm{M}$ sulfuric acid.

When air is used to produce the foams and for the atmosphere above the foams, we do not measure any dissolution of $\mathrm{Ag}$ which is in correlation with the electrochemical potential of the silver oxidation. To enable the oxidation of $\mathrm{Ag}$, we use ozone $\left(\mathrm{O}_{3}\right)$ a stronger oxidant. As ozone can easily attack the double carbon bond of the surfactant, we replace BrijO10 by Brij ${ }^{\circledR L} 23$ whose hydrophobic chain does not bear a double bond. This surfactant has a life expectancy of a few hours in the presence of ozone (28). To ensure that $\mathrm{O}_{3}$ is present both in the atmosphere and in the bubbles and to compensate for the foam collapse over time, the $\mathrm{O}_{3} / \mathrm{O}_{2}$ mixture is injected in a continuous manner using an ozonizer connected to a flow controller to maintain a constant gas flowrate. As shown in Table 2, using a sulfuric acid solution of $0.1 \mathrm{M}$ or $1 \mathrm{M}$ does not change the amount of dissolved silver, about $15 \mathrm{mg}$ after 5 hours. There are very few studies in the literature concerning the leaching of metallic silver by ozone that we can refer to evaluate the efficiency of our process (29-31). Vinals et al. (31) have studied the leaching of a silver powder with ozone dissolved in sulfuric acid solutions. Although the specific surface area of the powder used in their experiments is not given, we use the particle size to convert their results in rates in $\mathrm{mol} /\left(\mathrm{m}^{2} . \mathrm{s}\right)$ of Ag dissolved. Rate values of $2.10^{-6}$ and $2.10^{-7} \mathrm{~mol} /\left(\mathrm{m}^{2} . \mathrm{s}\right)$ were calculated for particles of diameter of $10 \mu \mathrm{m}$ or $1 \mu \mathrm{m}$ respectively. In our case, a rate of $10^{-5} \mathrm{~mol} /\left(\mathrm{m}^{2} . \mathrm{s}\right)$ can be determined using the surface area of the silver plate, which is at least an order of magnitude higher. This result consolidates the concept of using ozone foams to dissolve silver. Moreover, we note that the low dependency of the leaching rate upon the sulfuric acid concentration (in the $0.1-1 \mathrm{M}$ range) that we observe in Table 2 has also been reported by Vinals et al. (32). This result is likely to be due to the large excess of protons compared to dissolved ozone concentration in solution. Indeed the concentration of protons is also much higher than the concentration of dissolved silver and hence its consumption by the dissolution reaction is negligible. 
$\left[\mathrm{H}_{2} \mathrm{SO}_{4}\right] \quad \Delta \mathrm{m}_{\mathrm{Ag}} \quad\left[\mathrm{Ag}^{+}\right]$

(M) $(\mathrm{mg}) \quad(\mathrm{mM})$

\begin{tabular}{llll}
\hline Solution & $1 \mathrm{M}$ & 9 & 3 \\
& & & \\
\hline Foam & $0.1 \mathrm{M}$ & 15 & 6 \\
\hline & & & 6 \\
& $1 \mathrm{M}$ & 15 & \\
\hline
\end{tabular}

Table 2. Extension of the leaching foams to a noble metal, silver, $\mathrm{Ag}$ using a mixture of $\mathrm{O}_{3}$ and $\mathrm{O}_{2}$ for the foam bubbles. Mass of dissolved silver, $\Delta m_{A g}$ and silver ion concentration, $\left[\mathrm{Ag}^{+}\right]$ measured in $\mathrm{H}_{2} \mathrm{SO}_{4}$ solutions and foams after five hours.

\section{Complexing the $\mathrm{Cu}^{2+}$ with an anionic surfactant enables to improve the dissolution rate}

In the previous section we showed how the efficiency of metal leaching can be enhanced by improving the transfer of the oxidizing gas as a foam is used instead of a solution. Now we explore the potential of surfactants, another indispensable foam component, in the refinement of the oxidizing process. To increase the leaching rate of $\mathrm{Cu}$, we use a surfactant with a better affinity towards $\mathrm{Cu}^{2+}$ ions to shift the reaction equilibrium toward the release of $\mathrm{Cu}^{2+}$. While the neutral surfactants such as polyoxyethylene alkyl ether are not expected to form complex with $\mathrm{Cu}^{2+}$ ions, the use of anionic surfactants such as sodium dodecylsulfate is expected to lead to the complexation of two species with opposite electrostatic charges as shown by several studies in literature. 


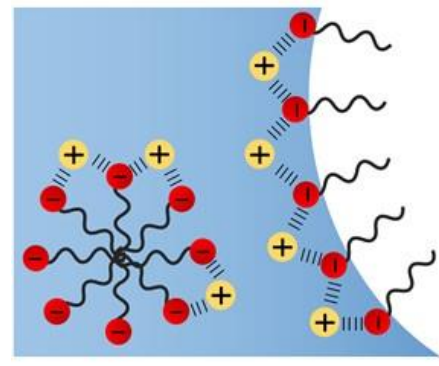

(a)
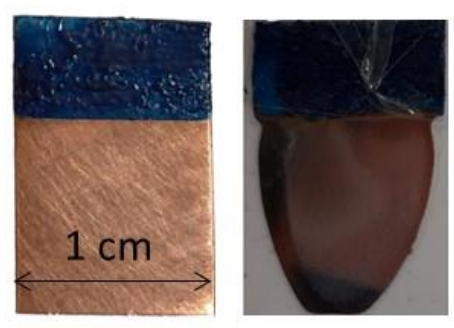

(c)

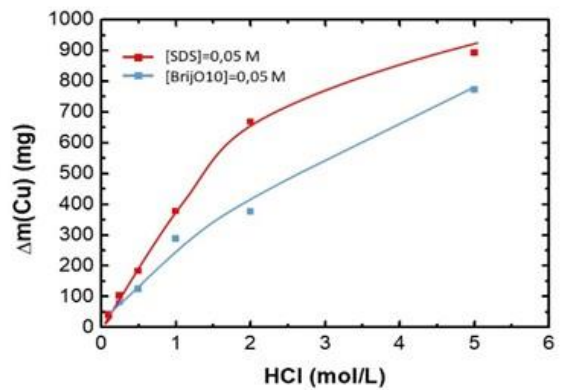

(b)

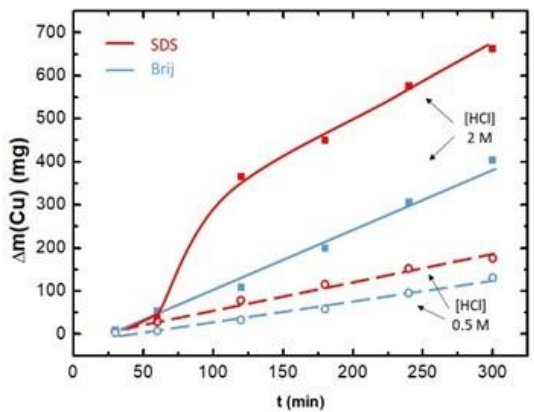

(d)

Figure 3. Dissolution of $\mathrm{Cu}$ in the presence of complexing surfactants. (a). Schematic drawing of the complexation of $\mathrm{Cu}^{2+}$ ions (yellow) with negatively charged SDS micelles in bulk solution and adsorbed SDS at air-water interfaces (b). Mass of dissolved $\mathrm{Cu}$ as a function of $\mathrm{HCl}$ concentration for a foam containing 0.05 M SDS or 0.05 M BrijO10. (c). Photographic image of the Cu plate before (left) and after (right) five hours of dissolution in $2 \mathrm{M} \mathrm{HCl}$ and $0.05 \mathrm{M}$ of SDS. (d) Mass of dissolved Cu as a function of time in foams stabilized either by $0.05 \mathrm{M}$ of BrijO10 or $0.05 \mathrm{MSDS}$ and for $\mathrm{HCl}$ concentrations of 0.5 and $2 \mathrm{M}$.

Indeed mixing a cupric salt with SDS is a method reported to synthesize a two-tail surfactants of $\mathrm{Cu}^{\mathrm{II}}$ (dodecylsulfate) 2 and interactions between SDS micelles and cupric ions are used for the extraction of $\mathrm{Cu}^{2+}$ ions from wastewater in a process called Micelle Enhanced Ultra Filtration (3234) (Figure 3a). Even though the $\mathrm{SDS}-\mathrm{Cu}^{2+}$ species are less stable than complexes between $\mathrm{Cu}^{2+}$ 
and ligands as EDTA or citric acid (30), the interaction is strong enough to promote the ultrafiltration of these cations over a large range of $\mathrm{pH}$.

In Figure 3b, we compare the amount of dissolved $\mathrm{Cu}^{2+}$ ions as a function of the $\mathrm{HCl}$ concentration for two surfactants, BrijO10 and SDS, at a concentration of $0.05 \mathrm{M}$. For both surfactants, the higher the hydrochloric acid concentration the higher the concentration of dissolved copper. The nonlinearity observed at high hydrochloric acid concentration with the SDS foams is probably due the decrease of the surface of the plate (Figure 3c). More interestingly, for every hydrochloric acid concentration, the use of SDS allows a faster copper dissolution of (Figure 3d). We thus demonstrate that the efficiency of the dissolution process strongly relies on the choice of the surfactant used to produce the foams. In addition to the interaction between the SDS micelles and

$\mathrm{Cu}^{2+}$ ions, it should be noted that the SDS can also interact with the layer of $\mathrm{Cu}_{2} \mathrm{O}$ present on the copper sample, with an impact on the dissolution rate. Indeed, the adsorption of SDS on $\mathrm{Cu}_{2} \mathrm{O}$ particles has been suggested by Villamil et al. (35) who showed that the protective layer of $\mathrm{Cu}_{2} \mathrm{O}$ on a copper electrode is partially dissolved in presence of SDS.

\section{Conclusion}

We have demonstrated that aqueous foams can oxidize and dissolve metallic copper in the presence of hydrochloric acid and an oxidizing gas such as $\mathrm{O}_{2}$ or $\mathrm{O}_{3}$. We show that controlling the atmosphere above the foams is crucial, as a fast exchange of gas between atmosphere and bubbles 
occurs, probably though the thin liquid films between the foam bubbles. Using foams, we achieve much higher dissolution rates than for aqueous solutions as the reactive gas transfers very quickly through the foams. This method enables to leach and remove a thickness of the order of $175 \mu \mathrm{m}$ from the copper plate, which is consistent with typical $\mathrm{Cu}$ thicknesses in PCBs. Furthermore, using $\mathrm{O}_{3}$ instead of $\mathrm{O}_{2}$ enables to extend the leaching foams concept to the dissolution of a noble metal like Ag. Moreover, by replacing a nonionic surfactant by a negatively charged surfactant which complexes the metal ions produced by the reaction, we show that the dissolution rate can be strongly enhanced. Hence, it can be foresees that a control of the selectivity of the process may be achieved by carefully choosing the surfactant formulation. This work is thus a very encouraging step toward the development of a hydrometallurgical process to recycle metals from electronic wastes based on foams, that is more environmentally friendly than classical hydrometallurgy in solution as it enables a strong reduction the volume of liquid used for the leaching process. From this proof of concept, many other developments can be considered. For example, tailored surfactants can be investigated to extend the synergy with their complexation characteristics. To address WEEE after a grinding step, a new set up designed to leach particles surface could be also studied. Another perspective would be to address other compounds, as metal sulfides, to take advantage of the oxidation by the foam in a leaching step.

AUTHOR INFORMATION

\section{Corresponding Author}

Cecile.monteux@espci.fr 
gregory.lefevre@chimieparistech.psl.eu

\section{Author Contributions}

The manuscript was written through contributions of all authors. All authors have given approval to the final version of the manuscript.

\section{Funding Sources}

We would like to acknowledge ANR-17-CE08-0016 FOAMEX as well as Ecole Doctorale ED 397 and French Ministry of Research for funding.

\section{ACKNOWLEDGMENTS}

We would like to acknowledge O. Diat, D. Bourgeois, D. Meyer, L. Girard, S. Guignot, S. Touze, S. Chapon, and M. Gras for fruitful discussions

\section{SYNOPSIS}

Aqueous foams enable to leach metals efficiently because of fast $\mathrm{O}_{2}$ transfer and they minimize effluent generation.

\section{LIST OF ACRONYMS}

$\mathrm{Au}$ - Silver

Brij010 - $\mathrm{C}_{18} \mathrm{H}_{35}\left(\mathrm{OCH}_{2} \mathrm{CH}_{2}\right)_{\mathrm{n}} \mathrm{OH}, \mathrm{n} \sim 10$ 
Brij®L23- $\left(\mathrm{CH}_{3}\left(\mathrm{CH}_{2}\right)_{10} \mathrm{CH}_{2}\left(\mathrm{OCH}_{2} \mathrm{CH}_{2}\right)_{n} \mathrm{OH}, \mathrm{n} \sim 23\right.$

$\mathrm{Cu}$ - Copper

EDTA - Ethylenediaminetetraacetic acid

$\mathrm{HCl}$-Hydrochloric acid

ICP-OES (Inductively Coupled Plasma - Optical Emission Spectrometry)

$\mathrm{N}_{2}$ - Nitrogen

$\mathrm{O}_{2}-$ Dioxygen

PCB - Printed circuit boards

SDS - Sodium Dodecyl Sulfate

WEEE - Waste from Electrical and Electronic Equipment

\section{REFERENCES}

REFERENCES

1. R.Widmer, H. Oswald-Krapfa, D. Sinha-Khetriwal, M. Schnellmann, H. Bönit, Global perspectives on e-waste. Environmental Impact Assessment Review 25 (5), 436-458 (2005). 10.1016/j.eiar.2005.04.001

2. B.K. Reck and T.E. Graedel, Challenges in metal cycling, Science, 337, (6090), 690-695, (2012) 10.1126/science.1217501 
3. A. Rigoldi, E.F. Trogu, G.C. Marcheselli, F.Artizzu, N. Picone, M. Colledani, P. Deplano, and A. Serpe, Advances in Recovering Noble Metals from Waste Printed Circuit Boards $\begin{array}{lllllll}\text { (WPCBs), ACS Sus Chem. Eng., } 7 & \text { (1), 1308-1317 (2019) }\end{array}$ DOI:10.1021/ACSSUSCHEMENG.8B04983

4. T. Hino, et al. Techniques to separate metal from waste printed circuit boards from discarded personal computers. Journal of Material Cycles and Waste Management 11 (1), $42-54$ (2009). DOI:10.1007/s10163-008-0218-0

5. Y. H. Zhou, and K. Q. Qiu. A new technology for recycling materials from waste printed circuit boards. Journal of Hazardous Materials 175 (1-3), 823-828 (2010). doi.org/10.1016/j.jhazmat.2009.10.083

6. P. Quinet, et al. Recovery of precious metals from electronic scrap by hydrometallurgical processing routes. Minerals \& Metallurgical Processing 22 (1), 17-22 (2005). 10.1007/BF03403191

7. F. P. C. Silvas, et al. Printed circuit board recycling: Physical processing and copper extraction by selective leaching. Waste Management $46 \quad 503-510 \quad$ (2015). 10.1016/j.wasman.2015.08.030

8. O. Tsydenova and M. Bengtsson. Chemical hazards associated with treatment of waste electrical and electronic equipment. Waste Management 31 (1), $45-58$ (2011). 10.1016/j.wasman.2010.08.014

9. S Ilyas, J Lee, R Chi Bioleaching of metals from electronic scrap and its potential for commercial exploitation, Hydrometallurgy 131, 138-143 10.1016/j.hydromet.2012.11.010

10. M. Kaya, Recovery of metals and nonmetals from electronic waste by physical and chemical recycling processes. Waste Management 57 64-90 (2016). 10.1016/j.wasman.2016.08.004 
11. Trucillo Paolo, Lancia Amedeo, D Amore Davide, Brancato Bruno, \& Di Natale Francesco. Selective Leaching of Precious Metals from Electrical and Electronic Equipment Through Hydrometallurgical Methods. Chemical Engineering Transactions 86, 1039-1044 (2021). 10.3303/CET2186174

12. Kamberović, Ž., Korać, M., Ivšić, D., Nikolić, V. \& Ranitović, M. Hydrometallurgical process for extraction of metals from electronic waste-part I: material characterization and process option selection. MJoM 15, 231-243 (2009) ISSN: 0354-6306

13. Awasthi, A. K. \& Li, J. An overview of the potential of eco-friendly hybrid strategy for metal recycling from WEEE. Resources, Conservation and Recycling 126, 228-239 (2017). 10.1016/j.resconrec.2017.07.014

14. J. Rubio, ML Souza, R.W. Smith, Overview of flotation as a wastewater treatment technique, Minerals processing, 15(3), 139-155 (2002) 10.1016/S0892-6875(01)00216-3

15. L. Stoica, et al. Removal of Ra-226(II) from uranium mining and processing effluents. Journal of Radioanalytical and Nuclear Chemistry 229 (1-2), 139-142 (1998). 10.1007/BF02389462

16. C. Dame, C. Fritz, O. Pitois, O., S. Faure, Relations between Physicochemical Properties and Instability of Decontamination Foams. Colloids Surf. Physicochem. Eng. Asp. 263 (1-3), 210-218 (2005) 10.1016/j.colsurfa.2004.12.053

17. F. Doyle, Ion flotation - its potential for hydrometallurgical operations. International Journal of Mineral Processing 72 (1-4), 387-399 (2003) 10.1016/S0301-7516(03)00113-3

18. C. Micheau, D. Dedovets, P. Bauduin, O., Diat, L. Girard, Environmental Science :Nano, 6, 1576-1584 (2019) 10.1039/C9EN00188C 
19. R. Houot, Beneficiation of Iron-Ore by Flotation - Review of Industrial and Potential Applications. International Journal of Mineral Processing 10 (3), 183-204 (1983). $10.1016 / 0301-7516(83) 90010-8$

20. X. Ma, et al. Effect of collector, $\mathrm{pH}$ and ionic strength on the cationic flotation of kaolinite. International Journal of Mineral Processing $93 \quad$ (1), $54-58 \quad$ (2009). 10.1016/j.minpro.2009.05.007

21. A.M. Gaudin, and D. W. Fuerstenau. Quartz Flotation with Anionic Collectors. Transactions of the American Institute of Mining and Metallurgical Engineers 202 (1), 66-72 (1955).

22. B. Burghoff, Foam fractionation applications. Journal of Biotechnology 161 (2), 126-137 (2012). 10.1016/j.jbiotec.2012.03.008

23. W.D. Lambert, et al. The effect of $\mathrm{pH}$ on the foam fractionation of beta-glucosidase and cellulase. Bioresource Technology 87 (3), 247-253 (2003). 10.1016/S0960-8524(02)002407

24. J. Lambert, R.Mosko, I.Cantat, P.Cloetens, J.A.Glazier, F.Graner, R.Delannay, Phys. Rev. Lett., 104, (2010) 10.1103/PhysRevLett.99.058304

25. C. Hadji, B.Dollet, H.Bodiguel, W.Drenckhan, B.Coasne, E.Lorenceau, Impact of Fluorocarbon Gaseous Environments on the Permeability of Foam Films to Air, Langmuir, 36, 44, 13236-13243 (2020) 10.1021/la803599z

26. M Kumar, J Lee, MS Kim, J Jeong, K Yoo, Leaching of metals from waste printed circuit borads (WPCBs) using sulfuric and nitric acids, Environmental Engineering \& Management Journal (EEMJ) 13 (10) (2014) 10.30638/eemj.2014.290

27. K. Khaled, S. A. Fadl-Allah, B. Hammouti, Materials Chemistry and Physics, 117, 148-155 (2009) 10.1016/j.matchemphys.2009.05.043 
28. Gieldowska-Bulska, A.; Perkowski, J.; Kos, L. The Application of Ozone in the Decomposition of Aqueous Solutions of Nonionic Surfactants. Ozone Sci. Eng., 26 (2), $217-$ 225. (2004) https://doi.org/10.1080/01919510490439636.

29. J. Vinals, A. Roca, M. Cruells, E. Juan, J. Casado, Procedure for selective leaching of metals. ES Patent 200101826 (2001)

30. William P. Van Antwerp, Phillip A. Lincoln, Precious metal recovery using ozone, US4752412A (1987)

31. J. Vinals, E. Juan, A. Roca, M. Cruells, J. Casado Leaching of metallic silver with aqueous ozone, Hydrometallurgy 76 225-232 (2005) 10.1016/j.hydromet.2004.11.001

32. E. Samper, M. Rodríguez, M. A. De la Rubia, D. Prats, Removal of Metal Ions at Low Concentration by Micellar-Enhanced Ultrafiltration (MEUF) Using Sodium Dodecyl Sulfate (SDS) and Linear Alkylbenzene Sulfonate (LAS). Sep. Purif. Technol., 65 (3), 337-342 (2009). https://doi.org/10.1016/j.seppur.2008.11.013.

33. A. Klimonda, I. Kowalska, I. Surfactant-Aided Membrane Process for Copper Ion Removal from Water Solutions. Environ. Prot. Eng., $44 \quad$ (1) (2008). https://doi.org/10.37190/epe180111.

34. Liu, C.-K.; Li, C.-W.; Lin, C.-Y. Micellar-Enhanced Ultrafiltration Process (MEUF) for Removing Copper from Synthetic Wastewater Containing Ligands. Chemosphere, 57 (7), 629-634 (2004). https://doi.org/10.1016/j.chemosphere.2004.06.035.

35. R. F. V. Villamil, et al., Effect of sodium dodecylsulfate on copper corrosion in sulfuric acid media in the absence and presence of benzotriazole, Journal of Electroanalytical Chemistry 472, 112-119 (1999) 10.1016/S0022-0728(99)00267-3 
For Table of Content only

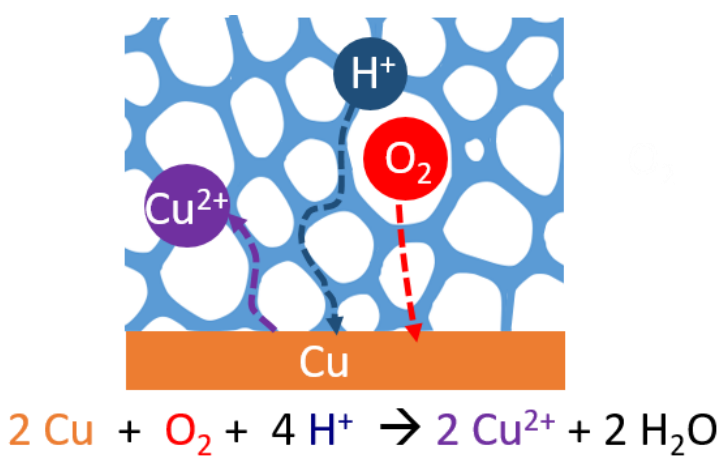

